\title{
Alzheimer Hastalığında Ketojenik Diyet Tedavisi
}

\author{
Gülsüm KARA*, Gül Eda KILINÇ**
}

\begin{abstract}
$\ddot{O} \mathbf{z}$
Alzheimer, bellek kaybı ve bilişsel fonksiyonlardaki azalma ile karakterize progresif bir nörodejeneratif hastalıktır. Patogenezinde yer alan glikoz hipometabolizmasının yıkıcı sonuçlarını engellemek, artmış oksidatif stresi ve inflamatuar yanıtı azaltmak ve mitokondriyal işlevleri geliştirmek amacıyla çeşitli diyet müdahaleleri kullanılmıştır. Bunlardan biri ketojenik diyet olmuştur. Ketojenik diyet, yüksek yağlı, düşük karbonhidratlı bir diyettir ve vücut enerjisinin yağlardan karşlanmasını sağlamaktadır. Alzheimer gibi nörodejeneratif hastalıklarda tedavi yöntemi olarak kullanılabileceği öne sürülmüsstür. Bunun en önemli nedenlerinden birisi beyinin glikoza bağımlılı̆̆ını azaltacak alternatif bir enerji kaynağı oluşturabilmesidir. Yağların mitokondride $\beta$-oksidasyonu sonucu keton cisimcikleri oluşmaktadır. Bu keton cisimcikleri beynin temel enerji kaynağı olan glikozun yokluğunda alternatif enerji kaynağı olarak kullanılmaktadır. Sonuç olarak glikoz metabolizması düzeltmekte, mitokondriyal fonksiyonlar gelişmekte, oksidatif stres azalarak sistemik inflamatuar azalmaktadır. Ketojenik diyetin $\beta$-Amiloid plak birikimi ve nörofibril yumak oluşumuna etkisi ise hala tartışmalıdır. Yapılan bazı hayvan modelli çalışmalarda $\beta$-Amiloid plak birikimini azalttığı sonucuna varılmıştır. Ancak bunun tersi sonuçlara sahip araştırmalar da mevcuttur. Dolayısıyla diyetin etkisini açılayabilmek için daha çok çalışmalara ihtiyaç duyulmaktadır. Bu derlemede ketojenik diyetin Alzheimer üzerine etkisini değerlendirmek amaçlanmıştır.
\end{abstract}

Anahtar Sözcükler: Alzheimer, beslenme, ketojenik diyet.

\section{Ketogenic Diet Treatment in Alzheimer's Disease}

\begin{abstract}
Alzheimer's is a progressive neurodegenerative disease characterized by memory loss and decreased cognitive function. Various dietary interventions have been used to prevent the devastating consequences of glucose hypometabolism in its pathogenesis, to reduce increased oxidative stress and inflammatory response, and to improve mitochondrial functions. One of them has been the ketogenic diet. The ketogenic diet is a high-fat, low-carb diet that provides the body's energy from fat. It has been suggested that it can be used as a treatment method in neurodegenerative diseases such as Alzheimer's. One of the most important reasons for this is that it can create an alternative energy source that will reduce the brain's dependence on glucose. Ketone bodies are formed as a result of $\beta$-oxidation of fats in mitochondria. These ketone bodies are used as an alternative energy source in the absence of glucose, the main energy source of the brain. As a result, glucose metabolism is corrected, mitochondrial functions develop, oxidative stress decreases and systemic inflammation decreases. The effect of the ketogenic diet on $\beta$-Amyloid plaque accumulation and neurofibrillary tangle formation is still controversial. In some animal model studies, it has been concluded that it reduces the accumulation of $\beta$-Amyloid plaque. However, there are also studies with opposite results. Therefore, more studies are needed to explain the effect of diet. In this review, it was aimed to evaluate the effect of the ketogenic diet on Alzheimer's.
\end{abstract}

Derleme Makale (Review Article)

Geliş / Received: 10.10.2021 \& Kabul / Accepted: 08.12.2021

DOI: https://doi.org/10.38079/igusabder.1007739

* Öğrenci, Ankara Üniversitesi, Sağllk Bilimleri Fakültesi, Beslenme ve Diyetetik Bölümü, Ankara, Türkiye,

E-posta: gulsuumkara@gmail.com ORCID https://orcid.org/o000-0002-8994-3851

${ }^{* *}$ Arş. Gör., Ankara Üniversitesi, Sağllk Bilimleri Fakültesi, Beslenme ve Diyetetik Bölümü, Ankara, Türkiye,

E-posta: dyt.edaa@gmail.com ORCID https://orcid.org/o000-0002-9068-3081 
Keywords: Alzheimer's, nutrition, ketogenic diet.

\section{Giriş}

Alzheimer, beynin çeşitli bölgelerinde gerçekleşen nöron dejenerasyonlarını takiben beyin fonksiyonlarında azalma görülen bir hastalıktır. Hastalığın evrimi hem progresif hem de geri dönüşsüz olup özellikle hafıza kaybı ile ortaya çıkar1,2. Dünyada artan yaşlı popülasyonuyla birlikte daha sık karşılaşılan Alzheimer hastalığının patogenezini açılamaya ilişkin birçok hipotez geliştirilmiştir. Bu hipotezlere göre çeşitli diyet türlerinin hastalığın ilerlemesine etkisi olup olmadığı araştırılmaktadır. Son yıllarda araştırmalara en çok konu olan beslenme çeşitlerinden biri ise ketojenik diyet olmuştur ${ }^{3}$. Ketojenik diyet, yüksek oranda yă̆ ve düşük oranda karbonhidrat içerir. Kan glikoz ve insülin seviyelerini düşürerek açlığı taklit eden mekanizmaya sahiptir. Alzheimer hastalarında görülen bozulmuş glikoz metabolizmasını ve mitokondri fonksiyonlarını iyileştirmeye, nöron kaybını azaltmaya yönelik tedavi stratejisi olarak düşünülmüştür. Çünkü bu faktörlerin $\beta$-Amiloid plak oluşumunu tetiklediği savunulmaktadır. $\mathrm{Bu}$ diyet ile vücudun enerji ihtiyacı glikoz yerine yă̆ asitlerinden karşılanmaktadır. Dolayısıyla beynin glikoza bağımlılığını azaltarak glikoz metabolizmasını geliştireceği düşünülmüştür. Aynı zamanda enerji kaynağı olarak kullanılan ketonlar glikoza kıyasla daha fazla Adenozin Trifosfat (ATP) ve daha az serbest radikal oluşturmaktadır. Buna karşılık inflamatuar yanıtlar ve sitokinler azalarak nörokoruyucu etki göstermektedir ${ }^{4,5}$. Bu çalışmanın amacı ketojenik diyetin Alzheimer üzerine etkisini değerlendirmektir.

\section{Ketojenik Diyet}

Ketojenik diyet, yüksek miktarda yă̆, düşük miktarda karbonhidrat içeren ve ketozisi aktive eden bir diyettir. Uzun yıllardır epilepsi hastalığında tedavi yöntemi kullanılmaktadır. Epilepsi hastalarında açlık durumunda nöbet gelişimi azalır. Açlık metabolizmasını taklit eden ketojenik diyet, nöbetleri azaltmak amacıyla kullanılmaktadır ${ }^{6}$. Ketojenik diyetin en önemli özelliği karaciğerde keton cisimciklerinin oluşmasını sağlamasıdır. Bu diyetin enerji kaynağını oluşturan yağlar, vücuda yeterli karbonhidrat alınmaması ve glikojen depolarının tükenmesinin ardından karaciğerde $\beta$-oksidasyona uğrayarak keton cisimciklerini oluşturmaktadır ${ }^{6,7}$. Bu ketozlar; $\beta$ hidroksibütirat, asetoasetat ve asetondur. Beynin temel enerji kaynağı olan glikozun yokluğunda oluşturulan keton cisimcikleri alternatif enerji kaynağı olarak kullanılmaktadır. Ayrıca beyin gelişiminde, hücre membranlarında, lipitlerin biyosentezinde ve hücre sinyallerinin oluşumunda görev almaktadır ${ }^{8}$. Temel olarak dört farklı ketojenik diyet türü bulunmaktadır. Bunlar, klasik ketojenik diyet, modifiye Atkins diyeti (MAD), orta zincirli trigliserit (MCT) diyeti, düşük glisemik indeks (LGI) diyetidir. Bu diyetlerin birbirinden farkı içerdikleri yă̆ türü ve miktarının farklı olmasıdır9. Ancak diyet türlerinin arasında etkinliği açısından önemli bir fark bulunmadığı belirtilmiştir. Diyet türünün seçiminde göze alınan nokta bireylerin yaşı, ekonomik olanakları ve besin tercihleri olmaktadır ${ }^{10}$.

\section{Ketojenik Diyetin Nöroprotektif Etki Mekanizması}

Ketojenik diyetin epilepsi nöbetlerini nasıl baskıladığına dair çeşitli araştırmalar yapılmıştır. Bu araştırmalara göre ketojenik diyetin olası etki mekanizmaları üzerine hipotezler oluşturulmuştur. En güçlü hipotez, keton cisimciklerinin doğrudan antikonvülsan etki hipotezidir. Ketojenik diyet ile vücut fonksiyonları için gereken enerji, karaciğer hücrelerinin mitokondrisinde yağların oksidasyonu ile gerçekleşir. Oksidasyon sonucu yüksek miktarda açığa çıkan ve biriken AsetilCoA, $\beta$-hidroksibutirat ve asetoasetatın sentezlenmesini sağlar. Bu ketonlar kan-beyin bariyerini geçerek beyin için alternatif bir enerji kaynağı olmaktadır ${ }^{11}$. Enerji kaynağı olarak 
kullanıldıklarında epilepsi nöbetlerinde azalma meydana geldiği gözlemlenmiştir. Ketonlar, koenzim Q10 seviyelerini azaltarak serbest radikal oluşumunu engeller. Glutatyon peroksidaz aktivitesini artırarak lipid peroksidasyonunu önler. Ayrıca glikozdan daha fazla enerji sağladığı için beyinde glikozdan daha etkin bir enerji kaynağı olduğu savunulmaktadır. Keton cisimciklerine ek olarak, çoklu doymamış yağ asitlerinin de antikonvülsan etki gösterdiği öne sürülmektedir. Çoklu doymamış yağ asitleri, sodyum veya kalsiyum membran kanallarını bloke ederek nöronal membran uyarılabilirliğini azalttığını böylece antikonvülsan etki gösterdiği düşünülmektedir. Aynı zamanda ketojenik diyetin antiinflamatuar etkiye sahip olduğunu belirten teoriler de bulunmaktadır ${ }^{12,6-8}$.

\section{Alzheimer Hastalığında Ketojenik Diyet Uygulaması}

Ketojenik diyetin epilepsi hastalı̆̆ının yanı sıra Alzheimer, Parkinson, Amiyotrofik Lateral Skleroz gibi nörodejeneratif hastalıkların tedavisinde de yararlı olduğu öne sürülmüştür3. Yapılan çalışmalar ile Alzheimer hastalığının patolojisine ilişkin metabolik değişiklikler ile sekonder gelişen değişiklikleri önlemekte veya geciktirmekte önemli rolü olabileceği desteklenmiştir ${ }^{13,14}$. Ketojenik diyetin Alzheimer hastalığındaki olası etki mekanizmaları aşağıda verilmiştir.

\section{Glikoz Metabolizması Üzerine Etkisi}

Alzheimer hastalarında ilerleyen bilişsel ve motor fonksiyonları dejenerasyonu, beyindeki bozulmuş glikoz metabolizmasıyla ilişkilendirilmiştir. Çünkü Alzheimer hastaları ve hastalık için genetik risk faktörü taşıan bireylerde serebral glikoz kullanımında azalma ile insülin sinyallerinde ve seviyelerinde değişiklik olduğu gözlemlenmiştirir. Düşük serebral glikoz kullanımı, beyinde $\beta$-Amiloid plak birikiminden ve nöron kaybından daha erken evrede başlamaktadır. Bu durumun nedeni henüz bilinmemektedir; ancak beyinde glikoz taşınmasında veya kullanımında ya da mitokondriyal fonksiyonlarda bozulmalar olabileceği tahmin edilmektedir. Beyin hücreleri, azalan glikoz alımı ve bozulan metabolizmaya karşı enerji bakımından yetersiz kalmaktadır. Bu durumda nöronal fonksiyonlar gittikçe kötüleşmekte ve bilişsel fonksiyon bozuklukları ilerlemektedir ${ }^{4}$. Yüksek miktarda işlenmiş karbonhidrat ve şeker alımıyla karakterize edilebilen yüksek glisemik diyetler, $\beta$-Amiloid birikim ile yakından ilişkilidir. Çünkü glisemik yükü yüksek diyetler periferik glikoz ve insülin sekresyonunda ciddi artışlara neden olur. $\mathrm{Bu}$ artış, $\beta$-Amiloid plak oluşumunu tetiklemektedir ${ }^{2}$. Alzheimer hastalarının beyin hücrelerindeki mitokondriyal DNA'ları oksidatif stresten hasar gördüğü ve mitokondrideki enzim etkinliğinin azaldığı belirtilmiştir. Bu durumun amiloid öncü proteinin işlevini değiştirerek $\beta$ Amiloid üretimini tetikleyebileceği ve bu birikim arttıkça mitokondri fonksiyonlarında da eş zamanlı bozulmaların artacağı düşünülmektedir ${ }^{13}$.

Glikoz hipometabolizması ve mitokondriyal disfonksiyon, beyinde enerji dengesizliğine neden olmaktadır. Beyin için oldukça verimsiz olan glikoz yerine ketonların kullanılması metabolizmayı iyileştirmektedir ${ }^{15}$. Keton cisimcikleri, glikoza göre daha fazla ATP üretilmesini sağlamaktadır. Artan mitokondriyal solunum ile birlikte ketonların nörokoruyucu etkileri ortaya çıkmaktadır. Ketosizle oluşan biyokimyasal değişiklikler, mitokondriyal fonksiyonları iyileştirerek, glikoza bağımlılığı azaltarak ve insülin duyarlılı̆̆ını arttırarak nöroprotektif fayda sağlamaktadır. Ketonlar, mitokondrinin detoksifikasyon etkisini arttırmaktadır. Mitokondriyal solunum zincirinde Nikotinamid Adenin Dinükleotid (NADH) oksidasyonunu arttırmakta ve Nikotinamid Adenin Dinükleotidin (NAD + / NADH) oksitlenmiş ve indirgenmiş formları arasındaki oranı dengelemektedir. Artmış NAD + / NADH oranı, mitokondriyi oksidatif strese karşı korumada önemli rol oynamaktadır ${ }^{4}$. Azalmış oksidatif stres beraberinde azalmış inflamutuar tepkiye yol açarak sistemik inflamasyonu da azaltmaktadır. $\mathrm{Bu}$ durum glikoza kıyasla ketonların mitokondriyal işlevi iyileştireceğini göstermektedir. Ek olarak ketojenik diyet, oksidatif stres 
oluşumunu etkileyen ana enzim olan glutatyon peroksidaz aktivitesini artırarak hipokampusta glutatyon düzeylerini yükseltmekte; gama-aminobütirik asit (GABA) fosforilasyonunu $\operatorname{artırmaktadır}^{16}$.

\section{Bilişsel Fonksiyonlara ve Demansa Etkisi}

Alzheimer hastalığının en temel belirtisi bellek kaybıdır. Hastalığın progresif sürecinde bellek kaybını takiben günlük hayatı oldukça zorlaştıracak belirtiler ortaya çıkmaktadır. Bu gelişime neden olan en büyük risk faktörü beyin dokusundaki hipometabolizma olduğu düşünülmektedir. Glikoz hipometabolizması sonucu beyinde kronik enerji eksikliği gözlenmesi; ilerleyen süreçlerde nöronal fonksiyonlarda bozulma ile bilişsel fonksiyonların azalmasına neden olmaktadır. Alzheimer hastaları ile yapılan bazı çalışmalarda, ketojenik diyetin beyine alternatif bir enerji kaynağı sağlayarak bilişsel fonksiyonları iyileştirdiği gösterilmiştir ${ }^{17,18}$. Bu çalışmalardan birkaçı Tablo 1'de özetlenmiştir. Bu sonuçlara göre ketojenik diyet uygulanmasının, kısa vadede Alzheimer hastalarında bilişsel performansı arttırdığını göstermiş̧ir. Bununla birlikte çalışmalar, nörolojik etkilerin, Alzheimer Hastalığı için en yaygın genetik risk faktörü olan ApoE\&4 alleline bağlı olduğunu ileri sürmektedir, çünkü bilişsel faydalar sadece ApoEع4 alleli taşımayan hastalar arasında gözlemlenmiştir. Ancak yakın tarihli bir vaka çalışması, heterozigot ApoEع4 alleli olan bir hastada ketojenik diyetten sonra bilişsel iyileşmeler bildirmiştir. Hafif bilişsel bozukluk ile birlikte Alzheimer hastalığı ve metabolik sendrom tanısı alan, heterozigot ApoEe4 alleli taşıyan 71 yaşındaki bir kadına 10 hafta düşük karbonhidratlı ve yüksek yağlı ketojenik diyet uygulanmıştır. 10 haftanın sonunda hastanın metabolik sendroma ilişkin biyokimyasal bulguları ve bilişsel fonksiyonları, beslenme ve yaşam tarzı müdahale protokolü ile pozitif bir korelasyon göstererek önemli ölçüde iyileştiği gözlemlenmiştir ${ }^{15}$.

Tablo 1. Alzheimer hastalarında ketojenik diyetin bilişsel fonksiyonlar üzerine etkisi ile ilgili yapılan çalışmalar

\begin{tabular}{|c|c|c|c|c|c|}
\hline Araştırmacılar & Amaç & $\begin{array}{l}\text { Örneklem } \\
\text { Grubu }\end{array}$ & Prosedür & Süre & Sonuç \\
\hline $\begin{array}{l}\text { Ohnuma ve } \\
\text { ark. }{ }^{19}\end{array}$ & $\begin{array}{l}\text { Oral ketojenik bir } \\
\text { formülün bilişsel } \\
\text { fonksiyonlar } \\
\text { üzerine etkisini } \\
\text { değerlendirmek }\end{array}$ & $\begin{array}{l}\text { Hafif-orta } \\
\text { evrede } \\
\text { sporadik } \\
\text { Alzheimer } 22 \\
\text { Japon hasta } \\
\end{array}$ & $\begin{array}{l}\text { Hastalara 90 gün } \\
\text { boyunca keton } \\
\text { formula } \\
\text { verilmiştir. }\end{array}$ & 90 gün & $\begin{array}{l}\text { Hiçbir hastada keton } \\
\text { formulanın tüketimi } \\
\text { bilişsel işlevi } \\
\text { iyileştirmemiştir. }\end{array}$ \\
\hline $\begin{array}{l}\text { Henderson ve } \\
\text { ark. }{ }^{20}\end{array}$ & $\begin{array}{l}\text { Oral ketojenik } \\
\text { formülün (AC- } \\
\text { 1202) bilişsel } \\
\text { fonksiyonlar } \\
\text { üzerine etkisini } \\
\text { değerlendirmek }\end{array}$ & $\begin{array}{l}\text { Hafif-orta } \\
\text { evre } \\
\text { Alzheimer } \\
\text { teşhisi alan } \\
152 \text { hasta }\end{array}$ & $\begin{array}{l}\text { Randomize çift } \\
\text { kör plasebo } \\
\text { kontrolllü } \\
\text { gerçekleştirilen } \\
\text { çalışmada } \\
\text { hastalara normal } \\
\text { diyeti ile birlikte } \\
\text { her gün AC-1202 } \\
\text { veya plasebo } \\
\text { verilmiştir. }\end{array}$ & 90 gün & $\begin{array}{l}\text { ApoEع4 alleli taşımayan } \\
\text { hastalarda plase-boya } \\
\text { kyyasla bilişsel } \\
\text { fonksiyonlarda önemli } \\
\text { gelişme gözlemlenmiştir. }\end{array}$ \\
\hline $\begin{array}{l}\text { Rebello ve } \\
\text { ark. }{ }^{21}\end{array}$ & $\begin{array}{l}\text { MCT diyetinin } \\
\text { bilişsel } \\
\text { fonksiyonlara } \\
\text { etkisini } \\
\text { gözlemlemek }\end{array}$ & $\begin{array}{l}\text { Hafif bilişsel } \\
\text { bozukluğu } \\
\text { olan } 58-78 \\
\text { yaş } \\
\text { aralığında } 6 \\
\text { hasta }\end{array}$ & $\begin{array}{l}\text { Randomize çift- } \\
\text { kör plasebo } \\
\text { kontrollü, } \\
\text { bireylere } 56 \mathrm{~g} / \mathrm{gün} \\
\text { MCT içeren } \\
\text { ketojenik diyet } \\
\text { veya plasebo } \\
\text { verilmiştir. }\end{array}$ & 24 hafta & $\begin{array}{l}\text { Sadece ApoE\&4 aleli } \\
\text { taşıyan ve plasebo aldığı } \\
\text { tespit edilen Alzheimer } \\
\text { hastalarında herhangi bir } \\
\text { bilişsel fonksiyonda } \\
\text { iyileşme } \\
\text { gözlemlenmemiştir. }\end{array}$ \\
\hline & $\begin{array}{l}\text { Hafif bilişsel } \\
\text { bozukluğa sahip } \\
\text { hastalarda } \\
\text { hiperketoneminin }\end{array}$ & $\begin{array}{l}\text { Ortalama } \\
\text { yaşı } 74,7 \\
\text { olan hafif- } \\
\text { orta bilişsel }\end{array}$ & $\begin{array}{l}\text { Çift kör plasebo } \\
\text { kontrollü } \\
\text { gerçekleştirilen } \\
\text { çalışmada }\end{array}$ & $\begin{array}{l}\text { Hastalara } 2 \\
\text { kere MCT } \\
\text { emülsiyonu } \\
\text { veya plasebo }\end{array}$ & $\begin{array}{l}\text { Sadece ApoEє4 alleli } \\
\text { taşımayan bireylerde kısa } \\
\text { vadeli bilişsel }\end{array}$ \\
\hline
\end{tabular}




\begin{tabular}{|c|c|c|c|c|c|}
\hline Reger ve ark. ${ }^{22}$ & $\begin{array}{l}\text { etkisini } \\
\text { gözlemlemek }\end{array}$ & $\begin{array}{l}\text { bozukluğa } \\
\text { sahip veya } \\
\text { Alzheimer } \\
\text { hastası } 20 \\
\text { kisi }\end{array}$ & $\begin{array}{l}\text { hastalara MCT } \\
\text { emülsiyonu veya } \\
\text { plasebo } \\
\text { verilmiştir. }\end{array}$ & $\begin{array}{l}\text { verilip 90 ve } \\
120 \text { dakika } \\
\text { sonra gözlem } \\
\text { yapılmıştır. }\end{array}$ & $\begin{array}{l}\text { performansta artış } \\
\text { gözlemlenmiştir. }\end{array}$ \\
\hline $\begin{array}{l}\text { Taylor ve } \\
\text { ark. }{ }^{23}\end{array}$ & $\begin{array}{l}\text { Ketojenik diyetin } \\
\text { fizibilitesini ve } \\
\text { bilişsel işlevler } \\
\text { üzerine etkisini } \\
\text { değerlendirmek }\end{array}$ & $\begin{array}{l}\text { Çok hafif, } \\
\text { hafif veya } \\
\text { orta evre } \\
\text { Alzheimer } \\
\text { hastası } 15 \\
\text { kişi }\end{array}$ & $\begin{array}{l}\text { Hastalara 90 gün } \\
\text { boyunca MCT } \\
\text { destekli ketojenik } \\
\text { diyet (\%70 yağ, } \\
\text { \%30 protein) ve } \\
\text { ardından } 30 \text { gün } \\
\text { boyunca normal } \\
\text { diyet verilmiştir. }\end{array}$ & 120 gün & $\begin{array}{l}\text { Çalışmayı tamamlayanlar } \\
\text { bilişsel değerlendirmede } \\
\text { önemli gelişme } \\
\text { göstermiştir ancak } \\
\text { hastaların ketojenik } \\
\text { diyeti sonlandırıp normal } \\
\text { diyete başlamaları ile } \\
\text { birlikte başlangıca } \\
\text { dönmüştür. }\end{array}$ \\
\hline Xu ve ark. ${ }^{24}$ & $\begin{array}{l}\text { Alzheimer } \\
\text { hastalarında MCT } \\
\text { kullanımının } \\
\text { bilişsel } \\
\text { fonksiyonlara } \\
\text { etkisini } \\
\text { değerlendirmek }\end{array}$ & $\begin{array}{l}\text { 57-87 yaş } \\
\text { aralığında } \\
\text { hafif-orta } \\
\text { evre } \\
\text { Alzheimer } \\
\text { hastalığı } \\
\text { teşhisi almış } \\
53 \text { hasta }\end{array}$ & $\begin{array}{l}\text { Randomize çift- } \\
\text { kör plasebo } \\
\text { kontrollü } \\
\text { gerçekleştirilen } \\
\text { çalışmada } \\
\text { hastalara günde } 3 \\
\text { kere MCT jölesi } \\
\text { veya plasebo } \\
\text { (kanola yağı) } \\
\text { verilmiştir. }\end{array}$ & 30 gün & $\begin{array}{l}\text { MCT grubunda } \beta \text { - } \\
\text { hidroksibütirat, } \\
\text { asetoasetat önemli } \\
\text { ölçüde yüksek çımıştır. } \\
\text { ApoE\&4 alleli taşımayan } \\
\text { hastalarda MCT’nin } \\
\text { bilişsel fonksiyonlar } \\
\text { üzerinde olumlu etkisi } \\
\text { olmuştur. }\end{array}$ \\
\hline Ota ve ark. ${ }^{25}$ & $\begin{array}{l}\text { Alzheimer hastalığı } \\
\text { olan hastalarda } \\
\text { MCT bazlı } \\
\text { ketojenik formülün } \\
\text { bilişsel işlev } \\
\text { üzerindeki etkisini } \\
\text { incelemek }\end{array}$ & $\begin{array}{l}\text { Ortalama } \\
\text { yaşı } 73,4 \\
\text { olan hafif- } \\
\text { orta evre } \\
\text { Alzheimer } \\
\text { hastalığı } \\
\text { tanısı almış } \\
\text { 20 Japon } \\
\text { hasta }\end{array}$ & $\begin{array}{l}\text { Hastalara tek } \\
\text { seferlik } 20 \mathrm{MCT} \\
\text { içeren ketojenik } \\
\text { formül veya } \\
\text { izokalorik plasebo } \\
\text { verilmiştir. Daha } \\
\text { sonra tüm } \\
\text { hastalara } 12 \text { hafta } \\
\text { boyunca } 50 \mathrm{~g} \\
\text { ketojenik formül } \\
\text { verilmiştir. }\end{array}$ & 12 hafta & $\begin{array}{l}\text { İlk denemede } 20 \mathrm{MCT} \\
\text { tüketen hastalarda } \beta \text { - } \\
\text { hidroksibütirat } \\
\text { seviyelerinde önemli artış } \\
\text { gözlemlenmiştir. Ancak } \\
\text { bilişsel fonksiyonlarda } \\
\text { değişiklik olmamışștır. } 12 \\
\text { haftalık deneme } \\
\text { sonucunda, çalışmayı } \\
\text { tamamlayan } 16 \text { hastada } \\
\text { bilişsel fonksiyon } \\
\text { testlerinde olumlu } \\
\text { sonuçlar } \\
\text { gözlemlenmiştir. }\end{array}$ \\
\hline $\begin{array}{l}\text { Philips ve } \\
\text { ark. }^{26}\end{array}$ & $\begin{array}{l}\text { Ketojenik diyetin } \\
\text { bilişsel } \\
\text { fonksiyonlara } \\
\text { etkisini } \\
\text { gözlemlemek }\end{array}$ & $\begin{array}{l}\text { Alzheimer } \\
\text { hastalığı } \\
\text { tanısı almış } \\
26 \text { hasta }\end{array}$ & $\begin{array}{l}\text { Hastalara } \\
\text { randomize } \\
\text { kontrollü } \\
\text { ketojenik diyet } \\
\text { veya plasebo } \\
\text { verilmiştir. }\end{array}$ & 12 hafta & $\begin{array}{l}\text { Ketojenik diyeti } \\
\text { uygulayan hastalar, } \\
\text { günlük işlev ve yaşam } \\
\text { kalitesinde iyileşme } \\
\text { göstermiştir. }\end{array}$ \\
\hline $\begin{array}{l}\text { Fortier ve } \\
\text { ark. }{ }^{27}\end{array}$ & $\begin{array}{l}\text { Ketojenik diyetin } \\
\text { bilişsel } \\
\text { fonksiyonlara } \\
\text { etkisini } \\
\text { gözlemlemek }\end{array}$ & $\begin{array}{l}\text { Hafif bilişsel } \\
\text { bozukluğa } \\
\text { sahip } 122 \\
\text { hasta }\end{array}$ & $\begin{array}{l}\text { Randomize } \\
\text { kontrollü yapılan } \\
\text { çalışmada } \\
\text { hastalara günde } 2 \\
\text { kere ketojenik } \\
\text { içecek veya } \\
\text { plasebo } \\
\text { verilmiştir. }\end{array}$ & 6 ay & $\begin{array}{l}\text { Ketojenik içecek tüketen } \\
\text { hastaların bilişsel } \\
\text { performansları ve kan } \\
\text { keton seviyeleri } \\
\text { plaseboya klyasla önemli } \\
\text { ölçüde artmıştır. }\end{array}$ \\
\hline
\end{tabular}

\section{Tau Proteinine ve $\beta$-Amiloid Plak Oluşumuna Etkisi}

Alzheimer hastalığının gelişmesine ve ilerlemesine neden olduğu kabul edilen nöroprotektif mekanizmalardan birisi $\beta$-Amiloid plak birikimidir. Fare modelli yapılan çalışmalarda ketojenik diyetin $\beta$-Amiloid seviyelerini düşürdüğü ve nöronlara girişinin engelleyerek hücre içi agregasyonunu azalttı̆̆ gözlemlenmiştir ${ }^{17,2}$. Kashiwaya ve ark., ketojenik diyetin $\beta$-Amiloid ve tau proteini üzerine etkisini inceledikleri çalışmada, transgenik 30 fareyi iki gruba ayırarak, 15 ay boyunca keton esteri içeren bir diyet veya karbonhidratla zenginleştirilmiş bir diyet vermişlerdir. 
Bu süreçte $\beta$-Amiloid ve tau proteini analizleri, davranış testleri, öğrenme ve hafıza testleri, korku koşullandırma testi yapılmıştır. Ketojenik diyet uygulanan farelerde $\beta$-hidroksibutirat seviyeleri önemli ölçüde yüksek çıktığı saptanmıştır. $\beta$-Amiloid ve tau proteini analizlerine göre ketojenik diyet verilen farelerde karbonhidratla zenginleştirilmiş diyetin verildiği farelere kıyasla $\beta$-Amiloid ve tau proteini birikiminin önemli ölçüde azaldığı saptanmıştır. Ayrıca bilişsel fonksiyonlarda ve davranış değişikliklerinde gelişmeler gözlemlendiği belirtilmiştir ${ }^{28}$. Benzer bir çalışmada, Alzheimer hastalığı gözlenen bir fare modelinde, ketojenik diyetin beyindeki $\beta$-Amiloid seviyelerini düşürerek toksisiteyi azalttığı ve mitokondriyal fonksiyonları geliştirdiği saptanmıştır. Öğrenmeyi ve hafızayı geliştirdiği belirtilmiştir ${ }^{18}$. Ancak yukarıdaki sonuçlarla çelişen bir başka çalışmada ketojenik diyetin transgenik fare modelinde kullanılmasıyla motor fonksiyonlarının iyileştiği fakat $\beta$-Amiloid plak seviyelerine ve tau proteinin birikmesine etkisi olmadığ gözlemlenmiştir. Bu sonuçlara göre ketojenik diyetin, $\beta$-Amiloid plak ve tau proteini birikiminin azalmasıyla pozitif korelasyon eğiliminde olduğu görülmektedir. Fakat yapılan çalışmaların sonuçlarına göre araştırmacılar halen fikir birliğine varamamışlardır. Çünkü çalışmaların yetersiz olduğu belirtilmiştiri ${ }^{17}$.

\section{Ketojenik Diyetin Olumsuz Etkileri}

Yetişkinlerde epilepsi nöbetlerini kontrol altına almak amacıyla uygulanan ketojenik diyet tedavisine ait çalışmalara göre tedavi sırasında en yaygın görülen yan etkiler gastroinstestinal sistem etkileri, kilo kaybı ve kan lipid profilindeki değişikliklerdir. Yetişkinlerdeki nörodejeneratif hastalıklarda ketojenik diyet kullanımına ilişkin yapılan çalışmalarda da benzer yan etkiler gözlemlenmiştir fakat veriler sınırlıdır ve yetersizdir. Çünkü az sayıda insan çalışması bulunmaktadır. Yapılan çalışmaların da katılımcı sayısının az olması ve takip süresinin kısa olması nedeniyle başka olası yan etkileri saptamak güç olmaktadır. Gastrointestinal yan etkiler arasında kabızlık, mide bulantısı, kusma, ishal, nadiren pankreatit ve iştah azalması görülmektedir29,30. Ketozis durumunda mide motor fonksiyonunda ve dolaşımdaki ghrelin konsantrasyonlarında azalma görülmektedir. Bireylerin tükettikleri besinlerin hacmi azalmakta, porsiyonları küçülmekte ve yemek yeme süreleri kısalmaktadır. Bu durum kilo kaybı ile sonuçlanmaktadır ${ }^{1}$. Ayrıca azalmış besin alımı azalmış protein alımına neden olabilmektedir. Bunun sonucunda proteinlerin katabolizmasında artma ve sentezinde azalma görülebilir. Azalmış karbonhidrat alımına bağlı vitamin ve mineral eksiklikleri ortaya çıkmaktadır. Posa alımı yetersiz kalmaktadır. Yetersiz posa alımı ile bağırsak sağlığı bozulmaktadır. Alzheimer hastalarında bağırsak sağlığını korumak, inflamasyonu azaltmak ve antioksidan kapasiteyi arttırmak adına oldukça önemlidir. Diyabetik hastalarda ise hipoglisemiye; insülin ünitelerinde azalmaya, tip 2 diyabet için verilen oral ilaçların dozlarının kesilmesine veya azaltılmasına neden olabilir. $\mathrm{Bu}$ nedenle insülin veya antidiyabetik ilaç kullanan hastalar dikkatle izlenmelidir32. Diğer potansiyel yan etkiler, osteopeni, osteoporoz, hipomagnezemi, hiponatremi, azalmış mineral kemik yoğunluğu, nefrolitiyazis, kardiyomiyopati, bozulmuş karaciğer fonksiyonlarıdır ve uzun süreli ketojenik diyet kullanımında bu yan etkilerle karşılaşılma olasıllı̆̆ yüksektirr16, 31, 33 .

\section{Sonuç ve Öneriler}

Alzheimer hastalığı, $\beta$-Amiloid plak birikimi, nörofibril yumak oluşumu ile karakterizedir. Glikoz hipometabolizması, mitokondriyal disfonksiyon, artmış oksidatif stres ve artmış inflamatuar yanıt da ayırt edici patofizyolojik özelliklerindendir. Azalmış glikoz alımı ve metabolizması ilerleyici bilişsel dejenerasyonla güçlü bir şekilde bağlantılıdır. Günümüzde hastalığı iyileştirecek veya gelişmesini geciktirecek herhangi bir tedavi yöntemi bulunmamaktadır. Diyet türleri ile glikoz hipometabolizmasına müdahale, potansiyel değiştirilebilir bir tedavi yöntemi olarak düşünülmektedir. Beyinde glikoz kullanımını sınırlandıran ketojenik diyetin nörolojik 
hastalıkların tedavisinde kullanımına ilişkin çalışmalar az olsa da bilişsel işlevleri iyileştirdiğine dair kanıtlar bulunmaktadır. Hayvan modelli çalışmalarda ise $\beta$-Amiloid plak birikimini önlediği ve motor fonksiyonlarını geliştirdiğini belirten çalışmalar vardır. Ancak çalışmaların süreleri kısadır. Bununla birlikte ketojenik diyetin sürdürülebilirliği zordur ve Alzheimer hastalarında uzun vadede kullanımının olumsuz etkileri olabilir. Bu nedenle ketojenik diyetin uzun vadeli potansiyel tedavi yöntemi olarak kabul etmek için daha çok çalışmalara ihtiyaç duyulmaktadır.

\section{KAYNAKLAR}

1. Eratne D, Farrand S, Kelso W, et al. Alzheimer's disease paper 1: Clinical update on epidemiology, pathophysiology and diagnosis. Australasian Psychiatry. 2018;26(4):347357. doi:10.1177/1039856218762308.

2. Pavon S, Lazaro E, Martinez O, et al. Ketogenic diet and cognition in neurological diseases: A systematic review. Nutrition in Clinical Care. 2021;79(7):802-813. doi: 10.1093/nutrit/nuaa113.

3. Rusek M, Czuczwar J, Koziol M, Pluta R. Ketogenic diet in Alzheimer's disease. International Journal of Molecular Sciences. 2020;20(16):3892. doi:10.3390/ijms20163892.

4. $\quad$ Lange K, Lange K, Gertruda E, Kanaya S, et al. Ketogenic diets and Alzheimer's disease. Food Science and Human Wellness. 2017;6(1):1-9. doi:10.1016/j.fshw.2016.10.003.

5. Batch J, Adkins A, Lamsal S, Sultan S, Ramirez M. Advantages and disadvantages of the ketogenic diet: A review article. Crues. 2020;12(8):1-8. doi:10.7759/cureus.9639.

6. Barzegar M, Afghan M, Behtari M, Khamaneh S, Raeisi S. Ketogenic diet: Overview, types, and possible anti-seizure mechanisms. An International Journal on Nutrition, Diet and Nervous System. 2019;24(4):1-10. doi:10.1080/1028415X.2019.1627769.

7. Uyar G, Şanlıer N. Çocukluk çağı dirençli epilepsilerinde ketojenik diyet uygulamalarının etkisi. Turk J Neurology. 2018;24:216-225. doi:10.4274/tnd.71473.

8. Barry D, Ellul S, Watters L, et al. The ketogenic diet in disease and development. $J$. Developmental Neuroscience. 2018;68(1):53-58. doi:10.1016/j.ijdevneu.2018.04.005.

9. Türk E. Ketojenik Diyet Kullanan Hastalarda Tedavi Etkinliğinin Değerlendirilmesi. [tıpta uzmanlık tezi]. Ankara, Türkiye: Ankara Çocuk Sağlığı ve Hastalıkları Hematoloji Onkoloji Sağlık Uygulama ve Araştırma Merkezi, Tıp Fakültesi; 2018.

10. Ilgaz F, Ardıçlı D, Günbey C, Topçu M, Yalnızoğlu D. Dirençli epilepside düşük glisemik indeksli diyet tedavisi: Olgu sunumu. Beslenme ve Diyet Dergisi. 2019;47(2):108-113. doi:10.33076/2019.BDD.1262.

11. Dhamija R, Eckert S, Wirrell E. Ketogenic diet. Canadian Journal of Neurology Sciences. 2013;40(2):158-167. doi:10.1017/So317167100013676.

12. Koh S, Auvin S, Dupuis N. Ketogenic diet and neuroinflammation. Epilepsy Research. 2020;167:1-8. doi:10.1016/j.eplepsyres.2020.106454.

13. McDonald T, Cervenka $M$. The expanding role of ketogenic diets in adult neurological disorders. Brain Sciences. 2018;8(8):148. doi:10.3390/brainsci8080148. 
14. McDonald T, Cervenka M. Ketogenic diets for adult neurological disorders. The American Society for Experimental NeuroTherapeutics. 2018;15:1018-1031. doi:10.1007/s13311-018-0666-8.

15. Morril S, Gibas K. Ketogenic diet rescues cognition in ApoE4p patient with mild Alzheimer's disease: A case study. Diabetes \& Metabolic Syndrome: Clinical Research \& Reviews. 2019;13(2):1187-1191. doi:10.1016/j.dsx.2019.01.035.

16. Pinto A, Bonucci A, Businaro R, Corsi M, Maggi E. Anti-oxidant and anti-inflammatory activity of ketogenic diet: New perspectives for neuroprotection in Alzheimer's disease. Journal of Antioxidants. 2018;7(5):63. doi:10.3390/antiox7050063.

17. Vinciguerra F, Graziano M, Frittitta L, Hagnas M, Tumminia A. Influence of the mediterranean and ketogenic diets on cognitive status and decline: A narrative review. Nutrients. 2020;12(4):1019-1042. doi:10.3390/nu12041019.

18. Koziol M, Pluta R. To treat or not to treat Alzheimer's disease by the ketogenic diet? That is the question. Neural Regeneration Research. 2020;15(5):857-858. doi:10.4103/16735374.268900.

19. Ohnuma T, Arai H, Higashiyama R. Benefits of use, and tolerance of, medium-chain triglyceride medical food in the management of Japanese patients with Alzheimer's disease: A prospective, open-label pilot study. Clinical Interventions in Aging. 2016;8(11): 29-36. doi: 10.2147/CIA.S95362.

20. Henderson S, Constantin L, Garvin F, Jones J, Vogel J. Study of the ketogenic agent AC1202 in mild to moderate Alzheimer's disease: A randomized, double-blind, placebocontrolled, multicenter trial. Nutrition\&Metabolism. 2009;10(6):31. doi:10.1186/17437075-6-31.

21. Rebello C, Greenway F, Johnson W, Keller J, Liu A. Pilot feasibility and safety study examining the effect of medium chain triglyceride supplementation in subjects with mild cognitive impairment: A randomized controlled trial. BBA Clinical. 2015;3:123-125. doi:10.1016/j.bbacli.2015.01.001.

22. Reger M, Hale C, Henderson S, et al. Effects of $\beta$-hydroxybutyrate on cognition in memory-impaired adults. Neurobiology of Aging. 2004;25(3):311-314. doi:10.1016/So197-4580(03)00087-3.

23. Taylor M, Burns J, Mahnken J, Sullivan D, Swerdlow R. Feasibility and efficacy data from a ketogenic diet intervention in Alzheimer's disease. Alzheimer's \& Dementia: Translational Research \& Clinical Interventions. 2018;4:28-36. doi:10.1016/j.trci.2017.11.002.

24. Xu Q, Zhang Y, Zhang X et al. Medium-chain triglycerides improved cognition and lipid metabolomics in mild to moderate Alzheimer's disease patients with APOE4-/-: A double-blind, randomized, placebo-controlled crossover trial. Clinical Nutrition. 2020;39(7):2092-2105. doi:10.1016/j.clnu.2019.10.017.

25. Ota M, Matsuo J, Ishida I et al. Effects of a medium-chain triglyceride-based ketogenic formula on cognitive function in patients with mild-to-moderate Alzheimer's disease. Neuroscience Letters. 2019;690:232-236. doi: 10.1016/j.neulet.2018.10.048. 
26. Phillips M, Deprez L, Mortimer G, et al. Randomized crossover trial of a modified ketogenic diet in Alzheimer's disease. Alzheimer's Research\&Therapy. 2021;13(51):1-12. doi: 10.1186/s13195-021-00783-x.

27. Fortier M, Castellano C, St-Pierre V et al. A ketogenic drink improves cognition in mild cognitive impairment: Results of a 6-month RCT. Alzheimer's\& Dementia. 2021;17(3):543-552. doi:10.1002/alz.12206.

28. Kashıwaya Y, Bergman C, Clarke K, et al. A ketone ester diet exhibits anxiolytic and cognition-sparing properties, and lessens amyloid and tau pathologies in a mouse model of Alzheimer's disease. Neurobiol Aging. 2013;34(6):1530-1539. doi:10.1016/j.neurobiolaging.2012.11.023.

29. Davis J, Ellison J, Fournakis N. Ketogenic diet for the treatment and prevention of dementia: A review. Journal of Geriatric Psychiatry and Neurology . 2020;34(1):3-10. doi:10.1177/0891988720901785.

30. McDonald T, Cervenka M. Ketogenic diets for adult neurological disorders. The American Society for Experimental NeuroTherapeutics. 2018;15:1018-1031. doi:10.1007/s13311-018-0666-8.

31. Wlodarek D. Role of ketogenic diets in neurodegenerative diseases (Alzheimer's disease and Parkinson's disease). Nutrients. 2019;11(1):169. doi:10.3390/nu11010169.

32. Dashti H, Mathew T, Al-Zaid N. Efficacy of low-carbohydrate ketogenic diet in the treatment of type 2 diabetes. Medical Principles and Practice. 2021;30:223-235. doi:10.1159/000512142.

33. Özdemir A, Demirel Z. Beslenme ve mikrobiyota ilişkisi. Journal of Biotechnol and Strategic Health Research. 2017;1:25-33. 